\title{
ANATOMIA PATOLOGICA DAS HEPATITES E CIRROSES $(*)$
}

\author{
DR. PAULO TIBIRIC̨Á \\ (Assistente do Departamento de Anatomia Patologica da Faculdade de \\ Medicina da Universidade de São Paulo. Diretor: Prof. Cunha Motı́a!.
}

Antes de mais nada, quero agradecer ao Departamento Cientifico Centro Oswaldo Cruz a honra do convite para substituir o prof. Cunha Mota na palestra de hoje. Vamos estudar as hepatites e cirroses.

Antes de mais nada, precisamos recordar ligeiramente a situação . do f:gado em rejaçãc ao mundo exterior e em relação ás outras porções do proprio organismo. Vemos que, se por um lado o figado está, por assim dizer, entrincheirado dentro do nosso organismo e portanto mais ou menos protegido dos traumatismos externos, por outro lado a situação dele em relação á circulação é o que ha de mais desfavoravel, porque, como sabemos muito bem, o figado recebe sangue da veia porta. Ora, este sangue da veia porta é recolhido em grande parte do tubo gastro-intestinal e assim sendo, vamos ter um sangue que mais ou menos entra em contacto com o que nós ingerimos. Por outro lado, nós ingerimos os alimentos os mais variados possiveis, alimentos proprios e improprios. Na parte impropria dos alimentos nós ivamos ter em quantidade maior ou menor germens e substancias toxicas. Parte destes germens pode atingir, pelo tubo gastro-intestinal, a circulação porta, e parte destas substancias toxıcas é tambem absorvida e cai nesta mesma circulação porta. De maneira que todas estas substancias nocivas ao organismo vão ter ao rigado. Logo, se por um lado ele está a coberto dos traumatismos extérnos, ele está por assim dizer aberto para as substancias toxicas e certa quantidade de germens. Mas se por um lado ele recebe estas substancias e estes organismos nocivos, por outro lado ele tem poder de lutar contra estas substancias e germens. Para a luta contra os germens ele tem em si uma grande quantidade de celulas do sistema reticulo-endotelial; para lutar contra as substancias toxicas ele tem o poder anti-toxico que é bastante conhecido. Vemos assim que se por um lado ele está exposto a muitas nocividades externas, ele tem o poder de se defender contra estas substancias. Depois precisamos ver em que porção do figado estes agentes podem atuar. Temos aqui (*) Conferencia realizada no Departamento Scientifico do Centro Academico Oswaldo
Cruz em Setembro de 1939. 
a considerar as celulas hepaticas e depois as celulas de Kupfer, o reticulo e finalmente os espaços porta. As celulas hepaticas em geral são atingidas pelos toxicos, sejam os toxicos imediatos absorvidos na luz do intestino, sejam as toxinas produzidas pelos germens absorvidos. Esta ação sobre o parenquima hepatico vai-se traduzir geralmente por processos degenerativos e estas celulas vão sofrer degenerações que vão constituir as chamadas hepatoses, processos estes até certo tempo atraz estudados entre as hepatites, mas depois que R.össle estudou bem a questão, ele fez para o figado o que tinha sido feito para o rim e colocou os processos predominantemente degenerativos na classe das hepatoses e os processos inflamatorios entre as hepatites. As celulas de Kupfer servem para a defeza contra os germens, pelo seu poder fagocitario, pelo poder de formação de substancias antitoxicas, etc. Os espaços porta vão sofrer principalmente quando as nocividades penetram no figado atravez as vias biliares. Com estas noções iniciais podemos entrar já no assunto, fazendo primeiro esta divisão entre hepatites $\epsilon$ hepatoses.

Como já disse, até certo tempo atraz as afecções hepaticas que tinham como substratum fenomenos degenerativos, eram incluidas nas hepatites. Não trataremos aqui da esteatose nem siquer da necrose aguda toxica ou atrofia amarela águda. Vamos passar já para os processos que são caracterisados pelas reações emanadas da rêde vascular ou do sistema reticulo-endotelial. Vamos cuidar das hepatites.

Em primeiro logar vamos tratar das hepatites serosas. Nestas hepatites serosas temos a considerar o edema do figado, que é encontrado muitas vezes em casos de infecção generalizada. Vemos que o figa,do fica aumentado de volume e com as funções mais ou menos perturbadas e vemos tambem que no parenquima ha una certa dissociação das células hepaticas que se mostram afrouxadas e mesmo por vezes podemos reconhecer mais ou menos bem as paredes dos seios renosos algo separados das traves de celulas hepaticas. Este processo pode tambem ser encontrado em casos de reações alergicas muito fortes.

Depois temos de falar das hepatites supurativas, que são, como o nome indica, itfflamações do figado en que se tem o acumulo de una quantidade notavel de neutrofilos e outras celulas inflamatorias, predominando, entretanto, os neutrofilos nos exsudatos. Neste caso, podemos ter dois tipos de inflamação supurativa: um bastante raro, que é o flegmão do figado, em que se tem uma, inflamação supurativa bastante intensa e extendendo-se a todo o parenquima hepatico é uma inflamação supurativa difusa do figado. No abcesso, que é a: mais comum, vamos ver que a inflamação supurativa se faz em fócos, e é seguida de fluidificação dos tecidos e das proprias celulas do exsudato, quer dizer, é scguida da formação de pús. Este abcesso póde ter origem diversa. E' assim que ele póde ser a consequencia de ferimentos: uma punhalada, facada, tiro, etc., que atinjam o figado e podem provocar então a formação de um abcesso. Entretanto, estes 
abcessos do figado são relativamente raros. Depois podemos ter abcessos no figado cuja via de entrada é a arteria hepatica. São os casos em que ha, por exemplo, uma septicemia e os germens em circulação no sangue chegam ao figado. Na maior parte das vezes o germen chegando ao figado é destruido pelas celulas do sistema reticulo-endotelial, daí a relativa raridade dos micro-abcessos no figado; mas outras vezes ou o sistema reticulo-endotelial já está com capacidade abaixada ou a quantidade de germens é maior e neste caso vàmos verificar o aparecimento de numerosos micro-abcessos localizados entre as traves hepaticas. Outras vezes vamos observar que o abcesso assume um tamanho maior como podemos ver nas figs. 1 e 2 .

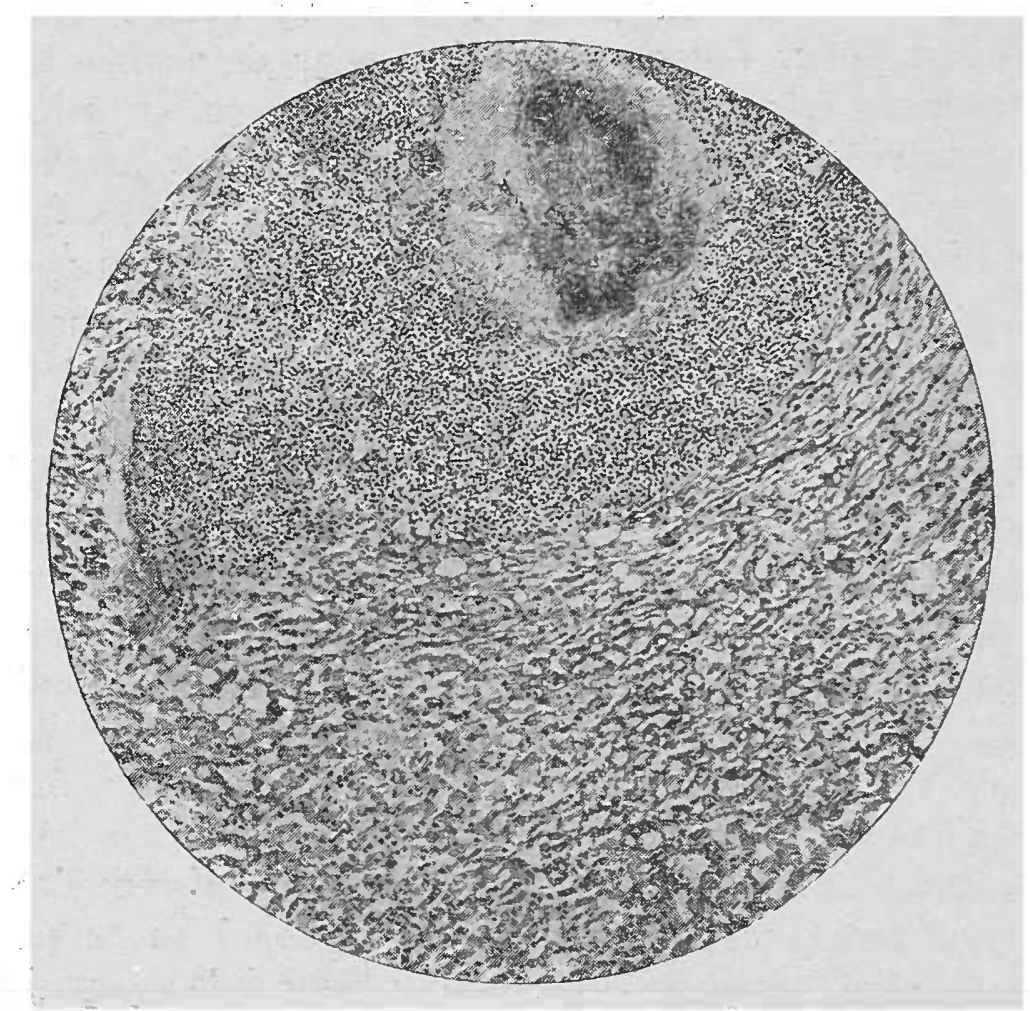

Fig. 1

Depois podemos ter como via de entrada para o figado a veia porta e esta é uma via muito importante, porque germens da supuração situados por exemplo em todo o vasto territorio da veia porta podem chegar ao figado; entre os casos mais comuns, cita-se o caso de abressu hepatico conscquente á apendicite. Vamos deixar de lato os abcessos amebianos, porque na maior parte das vezes nos abcessos amebianos não temos nada mais nada menos que uma necrose com liquefação dos tecidos e nião uma verdadeira supuração.

Como os germens podem chegar ao figado através a veia porta? Podem chegar de diversas maneiras. Pode, por exemplo, numa determinada ramificação da veia porta formar-se uma trombo-flebite que vem progredindo por esta ramificação até atingir a veia porta e o figado. Neste caso temos uma pileflebite que é uma flebite da veia 
porta que se foi propagando por continuidade até o figado. Neste caso vamos verificar a presença de numerosos abcessos em conexão com a veia porta e o trombo infectado dentro da veia porta. Outras

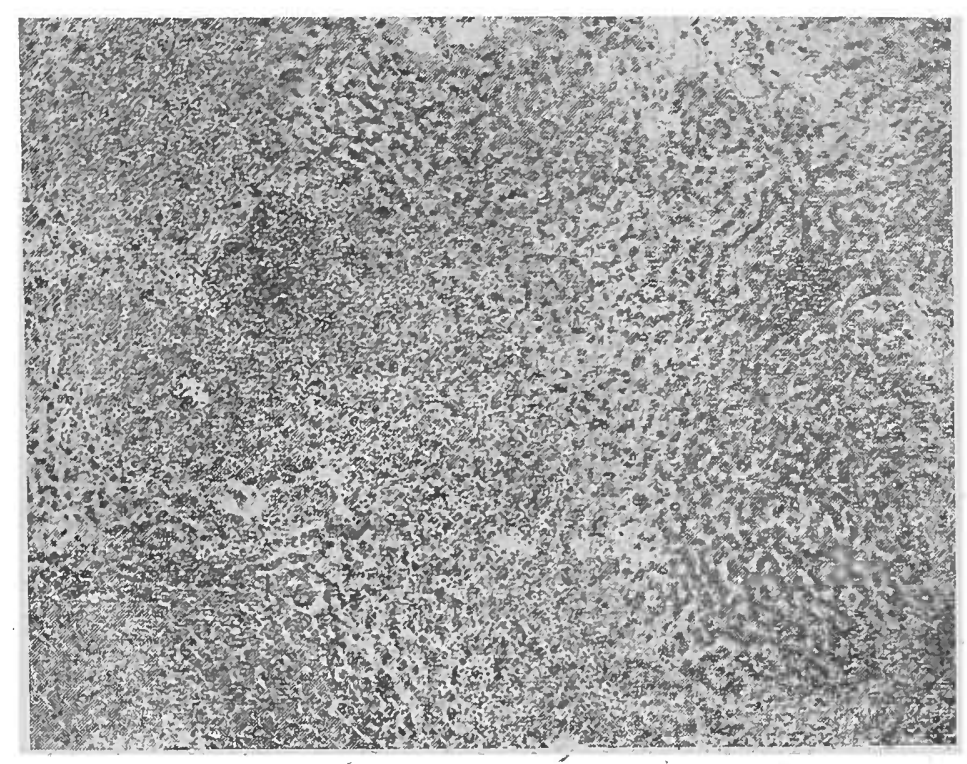

Fig. 2

vezes forma-se a pile-flebite num territorio infectado e depois um pequeno pedaço se desgarra e é levado com o sangue da veia porta para o figado e forma-se aí um abeesso unico ou maltiplos abecssos espalhados pelo figado. Todos estes tipos de abcessos preferem o lobo direito. (Fig. 3).

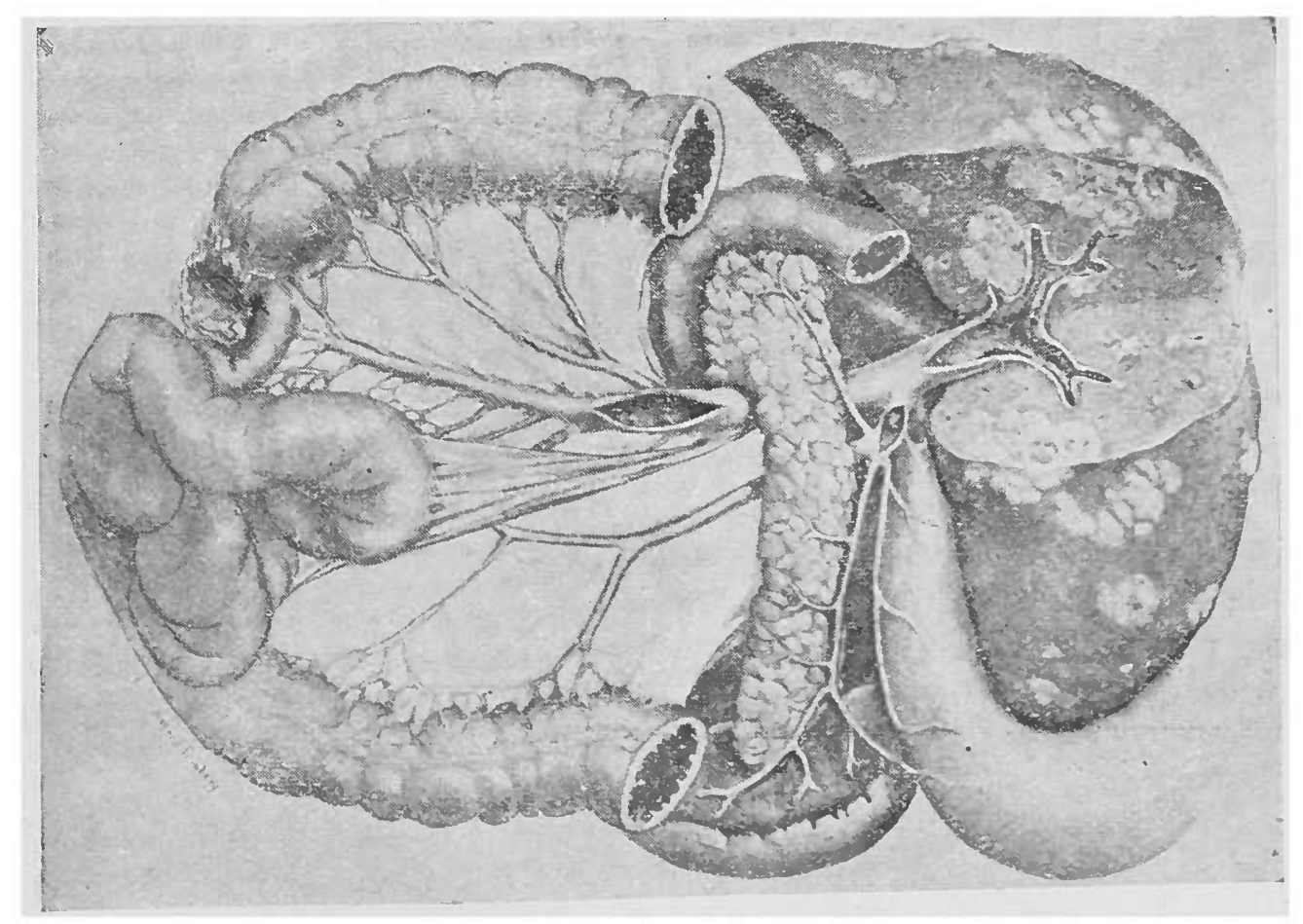

Fig. 3 
Um sistema venoso que póde tambem dar a entrada a germens da supuração para o figado são as veias supra-hepaticas; entretanto estes casos são muito raros, porque exigem de um lado a presença de trombo-flebite para o lado da veia cava superior ou para o lado do coração direito e por outro lado exige a necessidade de uma insuficiencia cardiaca, porque só nos casos de insuficiencia cardiaca é que podemos ter a passagem de um trombo da rveia cava superior para as ram ficações das veias supr-hepaticas. Um dos poucos casos citados é o de Kaufmann em que ele cita a existencia de uma tromboflebite dos seios da dura mater que deu um abcesso-hepatico. $\mathrm{O}$ trombo desceu pela veia cava superior, depois pela veia cava inferior e depois por embolia retrógrada atingiu a supra-hepatica.

Dutos biliares: a entrada pelos mesmos se faz geralmente por continuidade. Outras vezes, entretanto, se faz aos saltos, mas exige nesta segunda hipotese a presença de uma estase da bile. Se a bile estiver fluindo normalmente, o germen não pode subir, a não ser por continuidade. Neste caso vamos ter a presença de uma colangite supurativa e ao reclor dos dutos biliares vamos encontrar os abcessos. Estes abcessos muitas vezes apresentam um pús corado de verde, por causa da mistura do pús com a bile e a oxidação da mesma. Estes abcessos podem ser a consequencia de uma colecistite supurada ou podem ter uma outra origem, mas a origem mais comum é a colecistite supurada. Os calculos aqui têm uma grande importancia, principalmente o encravamento dos calculos e a respectiva estase. O prof. Alves Lima apresentou varios casos de abcessos hepaticos e em um deles apresentava um abcesso hepatico de natureza biliar, no meio do qual se encontrava um calculo. Vemos aqui que o calculo agiu bastante na questão da localização do abcesso.

\section{CIRROSES}

Vejamos em $10^{\circ}$ logar o que se deve entender por cirrose. Devemos entender por cirrose afecções do figado que trazem por consequencia uma modificação na construção celular hepatica, acompanhada de uma fibrose. De maneira que quando temos uma verdadeira remodelação do parenquima hepatico, acompanhada de fibrose, estamos deante de uma cirrose. Uma fibrose simples, sem alteração do parenquima hepatico, não podemos chamar de cirrose.

A que são devidas estas alterações do parenquima? São devidas de um ladio á destruição, e de outro á reconstrução do parenquima. Estas destruições muitas vezes se fazem em uma porção do parenquima e a, reconstrução em outra. Se temos construção aqui. 
e destruição ali, vamos ver que a primitiva arquitetura do orgão vai sofrer. Isso podemos compreender melhor nas figuras 4 e 5 .

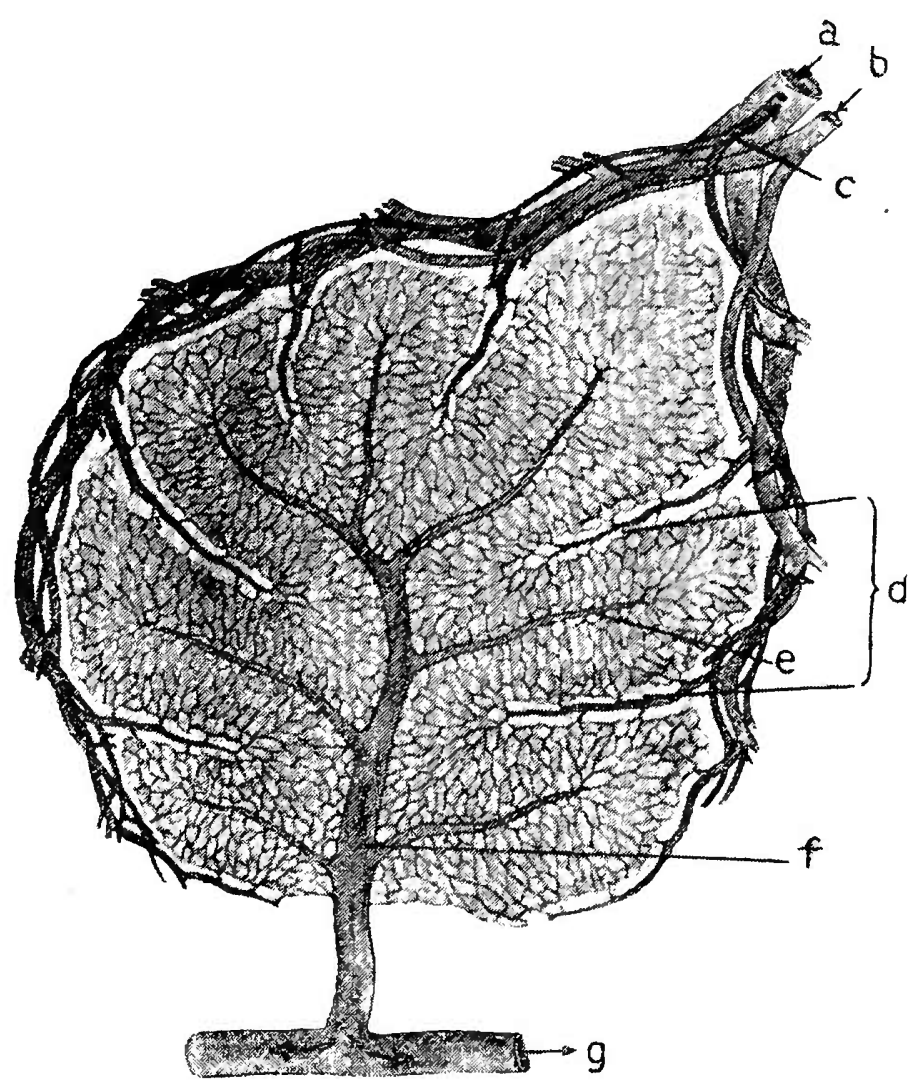

Fig. 4

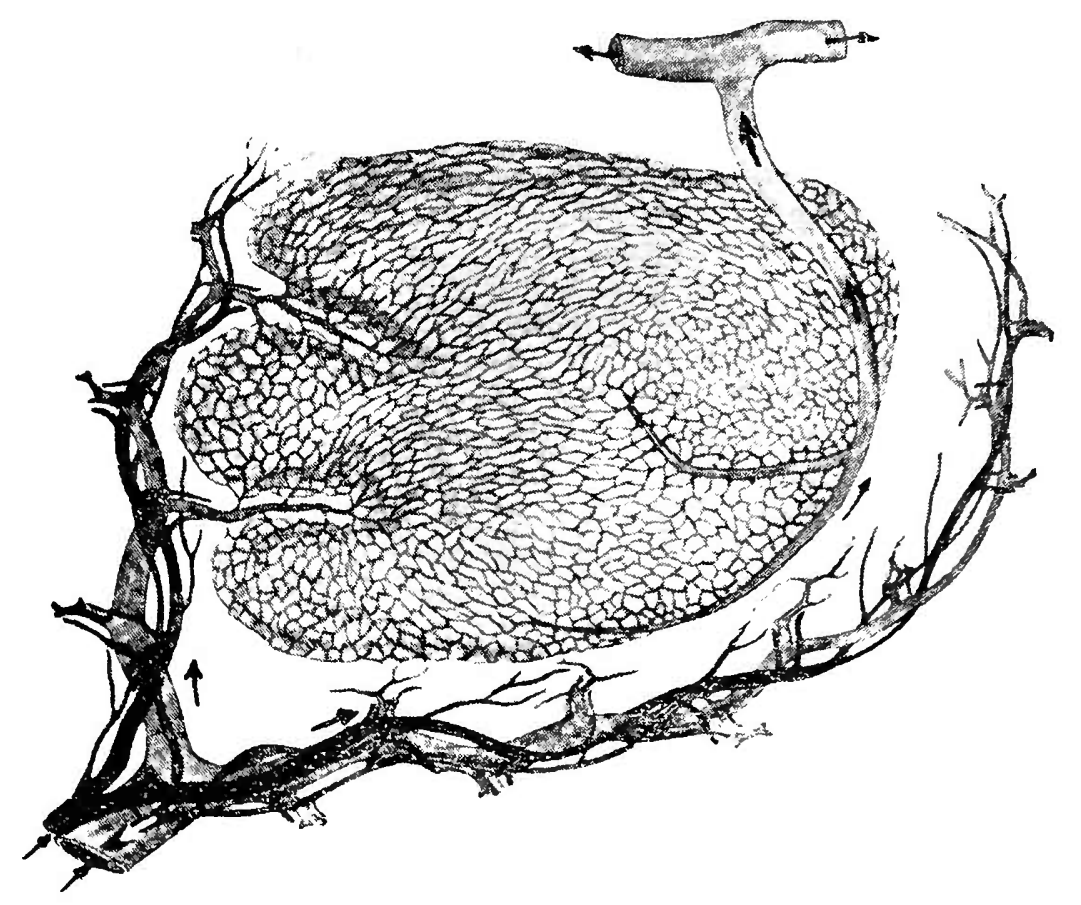

Fig. 5 
Portanto, vimos de um modo geral como se forman as cirroses; as cirroses formam-se á custa de destruições do parenquima acompanhadas de proliferação e de fibrose.

Qual é a causa das cirroses? A primeira causa invocada para as cirroses, é uma causa invocada para muitos males, que é o alcool. Nós todos sabemos que o alcool e o fumo servem de causa para uma porção de malẹs que não sabemos explicar como se originaram. $\mathrm{O}$ alcool e o fumo tomam, portanto, parte bastante larga. Em todo o caso, em relação ás cirroses, podemos dizer que grande parte delas. é devida a a alcool e é encontrada cm individuos que faziam uso bastante largo do mesmo, para não dizer que abusavam do alcool. A etiologia alcoolica das cirroses comporta mais considerações. Não é todo tipo de alcool que produz a cirrose. A cirrose parece ser produzida principalmente pelos áperitivos ou pelo Schanappsgenossen dos allemães. A bebida em grandes doses, como se costuma fazer com o vinho, ou cerveja, não tem a mesma importancia na etiologia das cirroses.

Outros fatores são lembrados na etiologia das cirroses. $\mathrm{Na}$ creança podemos relatar a etiologia tuberculosa. De fato, encontramos na creança a cirrose hepatica acompanhada de uma tuberculose mais ou menos difusa, peritoneal ou de outras serosas, constituindo o sindrome de Hutinel. O Prof. Cinhla Msta com o Dr. Leme da Fonseca publicaram entre nós um caso.

A etiologia pelo fumo já foi invocada para as cirroses.

O prof. Almeida Prado publicou um trabalho em 1915 em que ele relatava 2 casos de cirrose em 2 individuos da mesma nacionalidade e que moravam num mesmo quarto en que se manipulava o fumo em corda. Estudando estes casos, vimos que havia o uso moderado de alcool. E' claro que as aspirações do f'ımo falam em favor de uma etiologia tabagica.

Como é que agem estas substancias? Estas substancias vão agir para o lado do figado de um lado destruindo as celulas hepaticas, mas destruindo vagarosamente, e de outro lado, estimulando a proliferação conjuntiva. A principio pensou-se que na cirrose havia qualquer cousa que estimulava a proliferação conjuntiva que trazia para o parenquima hepatico uma atrofia (por compressão), mas isso năo é verdade, porque se fosse só assim não explicaria a grave remodelação da arquitetura hepatica. Temos de admitir que o agente traz de um lado destruiçãa da celula hepatica e do outro, proliferação conjuntiva. O figado tem $\mathrm{km}$ grande poder de restauração; na necrose aguda toxica, que por vezes destrói grande porção do parєnquima, este parenquina póde ainda ser renovado.

Vejamos agora como podemos subdividir as cirroses.

A questão é das mais complicadas para se faz rr ,porque cada tratado e cada autor que se lê dá uma divisão completamente diversa 
do outro. Vamos seguir preferentemente a divisäo dada por Dietrich que é a mais moderna e que me parece mais de acordo com os fatos que temos observado; vamos acrescentar algumas modifıcações nesta divișão.

Vamos considerar em $1 .^{\circ}$ logar a cirrose atrofica. Nessa cirrose atrofica temos um tipo de cirrose caracterisado principalmente por uma fibrose, acompanhada de alterações da arquitetura hepatica, e di-minuição de volume do orgão. Assim vamos ter aspectos bastante caracteristicos (Fig. 6). Como consequencia da fibrose vemos perções do parenquima hepatico se elevando relativamente e o orgão diminuido de volume vai apresentar uma superficie mais granulosa, com granulos de tamanho bastante variado. No caso de cirrose atrofica vemos portanto o figado diminuido de volume, com a superficie granulosa e ao fazermos o corte, a faca encontra resistencia e póde mesmo cantar. $\mathrm{Na}$ superficie de corte vemos o parenquima de côr as mais das vezes amarela, de um amarelo-sujo, o qual aliás deu o nome ao processo, e o parenquima dividido em ilhotas de tamanho irregular por esta fibrose. Nos casos de cirrose de Laennec vamos encontrar en geral a presença de ascite e congestão porta. Esta ascite e congestão porta são facilmente explicadas pela interrupção de grande parte da circulação porta. Nestes casos ou não encontramos ictericia ou encontramos uma ictericia relativamente pequena, isto porque vimos que os dutos biliares formados entram em conexão com o parenquima hepatico néo-formado. Por outro lado, encontramos uma esplenomcgalia mais ou menos moderada, que em parte

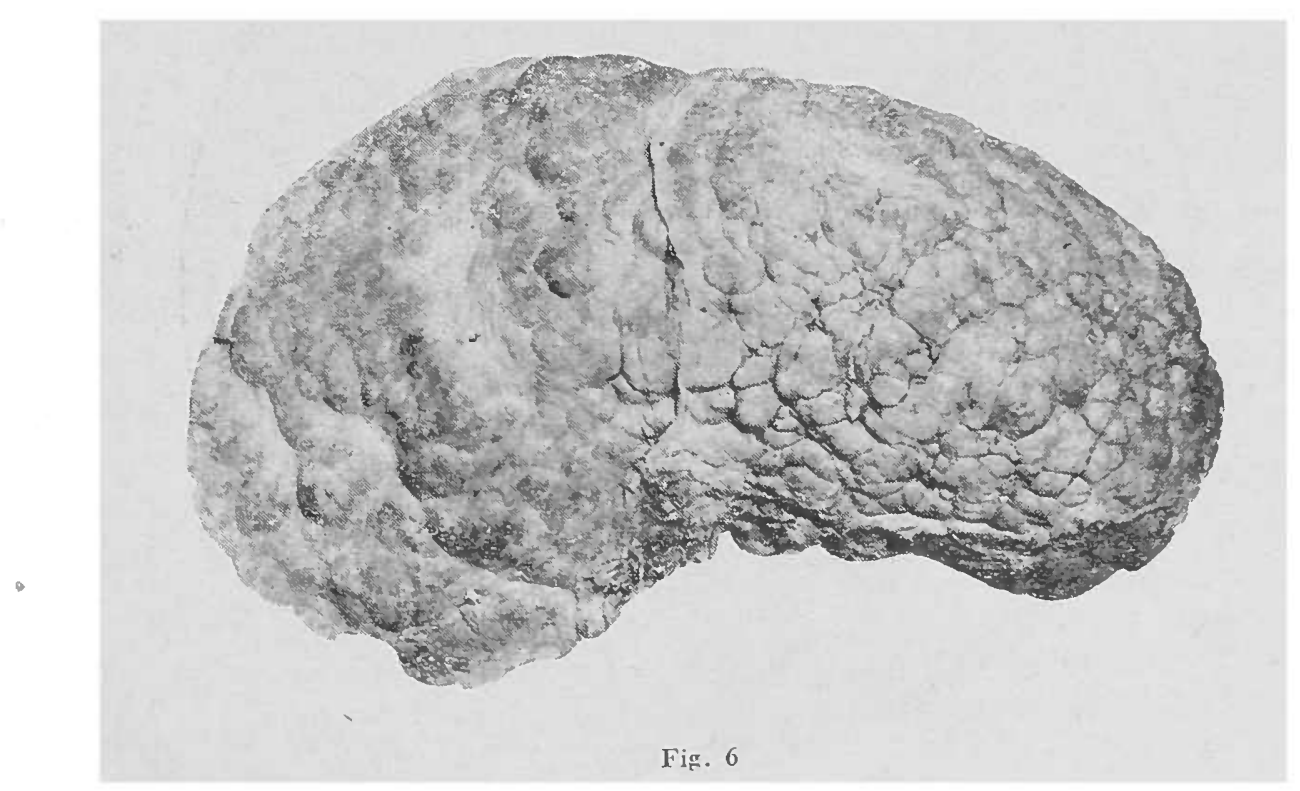

corre por conta da congestão passiva e em parte por uma hiperplasia da polpa vermelha. Esta hiperplasia parece indicar que o toxico que agiu sobre o figado, agiu tambem sobre o sistema reticulo-endotelial do baço. 
Passamos agóra para as cirroses hipertroficas, que decorrem com aumento de volume do orgão. Entre estas cirroses temos de considerar as cirroses hipertroficas de tipo gorduroso e a cirrose de Hanot. Nestas cirroses de tipo hipertrofico gorduroso temos uma cirrose do tipo anterior, mas em que não ha uma diminuição de volume do orgão, isto porque junto com a cirrose temos uma esteatose infiltrativa que é facilmente explicada, porque o alcoolismo ao lado da cirrose gerou uma esteatose infiltrativa. Na cirrose de $\mathrm{Ha}$ not, tipo bastante raro, temos um quadro diferente, porque na cirrose de Hanot o tecido fibroso não se contenta em circumscrever as ilhotas de parenquima, mas ele tamben cresce em pleno parenquima, entre as traves hepaticas, como vemos na fig. 7. A consequencia disto é que na cirrose de Hanot vamos ter uma ictericia que é explicada não só pelo fato do tecido fibroso fechar os dutos biliares, como tambem é explicada pelas alterações celulares do parenquima hepatico serem mais graves e darem uma ictericia que até certo ponto póde ser considerada uma ictericia de difusão. Nesta cirrose de Hanot temos uma ictericia, a ascite é pequena, porque as alteraçõe $e_{S}$ hepaticas são mais para o lado dos dutos que da circulação e a circulação porta póde entrar em contacto com a circulação das vias sub-lobulares.

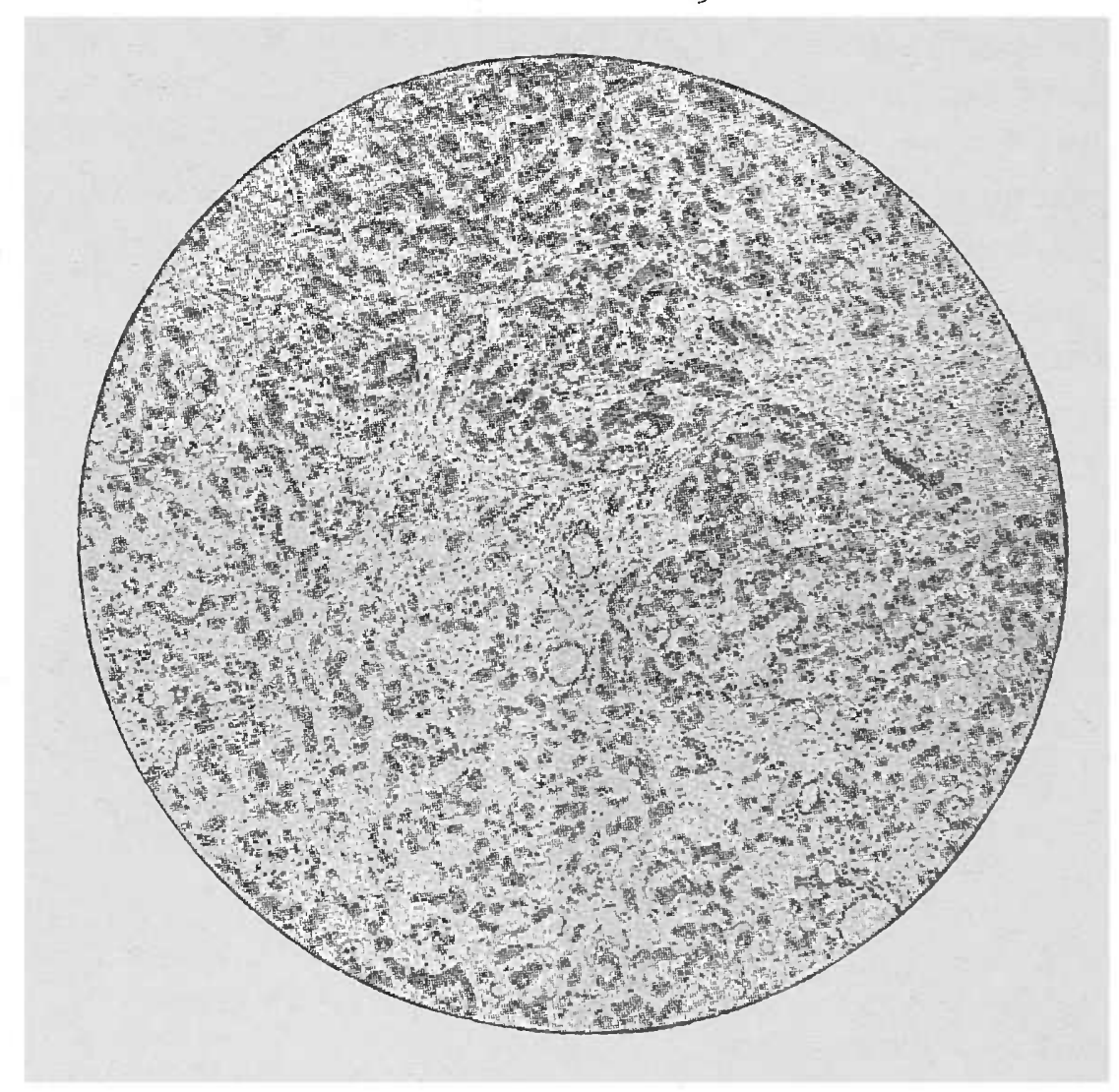

Fig. 7

Cirrose biliar. Alguns consideram a cirrose de Hanot como uma cirrose de tipo biliar, mas outros separam esta cirrose da de Hanot. De fato, na cirrose biliar vamos ter antes uma peri-angio- 
colite cronica e fibroplastica que uma cirrose. $O$ tecido cresce ao redor dos dutos e cresce para fóra. Aqui temos antes um processo Gos dutos biliares qu verdadeiramente uma cirrose. Estas cirroses biliares são produzidas na maior parte das vezes por estase da bile, principalmente devida a calculos, tumor, etc.

Cirrose pigmentares. São cirroses semelhantes ás outras cirroses, principalmente á de Laener, mas ao lado do quadro da cirrose temos um deposito mais ou menos consideravel de pigmento que póde ser a hemosiderina e então vamos ter a cirrose pigmentar angionemotoxica, porque temos alterações para o lado do sangue, libertando-se hemoglobina que vai dar a hemosiderina. Temos tambem alterações biliares. Podemos ter cirroses pigmentares en que o pigmento é a hematoidina, que são as cirroses encontradas na hemocromatose e diabete.

As cirroses que encontramos no mal de Banti são semelhantes á de Laenec, mas com uma esplenomegalia tipica, com fibroadenia e fibrose para o lacio rla polpa; é uma esplenomegalia quie precede á cirrose e alem dela temos uma anemia e alterações para. o lado do aparelho gastro-intestinal. Nestes casos a esplenectomia vem produzir uma, parada no desenvolvimento da cirrose.

Para terminar, vamos estudar algumas formas mais raras de cirrose. Em 1. ${ }^{\circ}$ logar está a cirrose da congestão passiva ou a cirrose cardiaca dos autores francezes. Neste caso a cirrose é a consequencia de uma congestão passiva de longa duração e intensidade. A congestão passiva altera o parenquima hepatico, destruindo-o e quando esta destruição chega a um estado muito avançado, o resto do parenquima entra en regeneração e daí a possibilidade de uma restauração do parenquima e uma fibrose. Esta fibrose se faz por uma transformação das "gitterfasern"” em fibras colag€nas.

Cirrose por necrose toxica — é a achada nas formas subaguda e crónica da atrofia amarela dofigado. Na forma aguda, em geral temos a morte. Entretanto, nas formas menos intensas e nas formas de decurso cronico temos de um lado uma destruição mais vagarosa que a destruição aguda toxica, porem mais rapida que os outros tipos de cirrose. De modo que temos destruição, reconstrução e fibrose. Esta cirrose entretanto, apresenta nodulos bastante grandes e ao microscopio encontramos areas de necrose e de degeneração.

Dutro tipo de cirrose rara é a que encontramos na molestia de Wilson, em que ao lado da cirrose encontramos uma, degeneração cus nucleos da base do cerebro.

Temos ainda as cirroses provocadas por Trematodeos, principalmente pelos ovos. Entre nós encontramos principalmente a cirrose produzida pelo Schistosoma mansoni. Os ovos dele se embolizam pelas ramificaçõs da veia porta e depois ao redor delas vai-se produzir uma cirrose. Neste caso, a superficie do figado é lisa, mas 
vamos encontrar um pontilhado muito intenso, de côr branca, que corresponde ás porções em que os ovos fizeram uma cirrose ao redor.

A questão das cirroses por Trematodeos tem importancia pratica, porque se póde formar em consequencia um carcinoma a, nivel dos nódulos de proliferação. Nas cirroses por Trematodeos, o aparecimento do cancer é muito comum, como acontece na cirrose produzida pelo Opistorchis felineus no Kurishes Haff na Prussia. 